Research Paper:

\title{
Effect of Core Stability Exercise and Vitamin D Intake on Liver Enzymes Activities in Women With Chronic Low Back Pain
}

\author{
Seyyed Javad Hashemi Sangatrashani ${ }^{1}\left(\mathbb{D},{ }^{*}\right.$ Masoumeh Habibian $^{1} \mathbb{( D}$, Seyyed Jafar Moosavi $^{1}$ (i)
}

1. Department of Physical Education, Qaemshahr Branch, Islamic Azad University, Qaemshahr, Iran.

\begin{tabular}{|c|c|}
\hline $\begin{array}{l}\text { Use evour devive to scan } \\
\text { and read the article online }\end{array}$ & Citation Hashemi Sangatrashani SH, Habibian M, Moosavi SJ. Effect of Core Stability Exercise and Vitamin D Intake on Liver Enzymes \\
\hline atsing & $\begin{array}{l}\text { Activities in Women With Chronic Low Back Pain. Journal of Inflammatory Diseases. 2020; 24(4):332-345. https://doi.org/10.32598/ } \\
\text { JQUMS.24.4.2 }\end{array}$ \\
\hline aryas & dol'https://doi.org/10.32598/JQUMS.24.4.2 \\
\hline
\end{tabular}

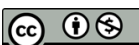

Received: 21 Jun 2020

Accepted: 23 Sep 2020

Available Online: 01 Oct 2020
Keywords:

Exercise, Liver, Low

back pain, Serum

Transaminases,

Vitamin D

\section{A B STRACT}

Background Deficiency or insufficient level of vitamin D is very common in patients with liver disease, and is closely related to musculoskeletal pains, including low back pain.

Objective The current study aims to investigate of the activity of liver enzymes in women with chronic low back pain following core stability exercises and vitamin D intake.

Methods This clinical trial was conducted on 48 women (Mean \pm SD of age $=36.59 \pm 5.50$ years) in 2019 selected by using a convenience sampling method. They were randomly divided into four groups of control, vitamin D, exercise and combined (exercise +vitamin D). The last two exercise groups performed 8 weeks of core stability exercises with different intensities. The vitamin $D$ and combined groups received $50,000 \mathrm{lU} /$ week of vitamin D for 8 weeks. Alanine aminotransferase (ALT), Aspartate aminotransferase (AST) and Alkaline phosphatase (ALP) activities were measured before and after the interventions. Data were analyzed by using paired t-test and one-way ANOVA.

Findings Eight weeks of core stability exercises, vitamin D intake, and the combined exercise and vitamin D supplementation caused a significant reduction in the activity of AST, ALT, and ALP enzymes. The combined intervention induced more reduction in the AST and ALP activities compared to other two groups received exercise and supplementation alone, and the decrease in ALT activity following the combined intervention was higher compared to the exercise group.

Conclusion It seems that the core stability exercises, vitamin D intake, and combination of exercise and vitamin D supplementation can improve liver function in women with chronic low back pain who have vitamin $\mathrm{D}$ deficiency by reducing the activity of liver enzymes. The combined intervention has greater effectiveness in improving liver function.

\section{Extended Abstract}

\section{Introduction}

hronic low back pain is an outstanding physical problems is correct in industrialized and developing countries [1]. Selfmedication for low back pain is a barrier to its effective diagnosis and management [2]. Deficiency or insufficient level of vitamin D can cause or worsen low back pain and muscle spasm [3]. In addition, vitamin D deficiency is associated with chronic musculoskeletal pain including low back pain [4]. More than $90 \%$ of vitamin D is synthesized under ultraviolet radiation in human skin [5]. The vitamin D receptors in non-parenchymal cells of the liver, and the local conversion of absorbed vitamin $\mathrm{D}$ to

\section{* Corresponding Author:}

Masoumeh Habibian

Address: Department of Physical Education, Qaemshahr Branch, Islamic Azad University, Qaemshahr, Iran.

Tel: +98 (11) 42155025

E-Mail: habibian_m@yahoo.com 
its active form in adrenal and liver tissues indicate a possible effect of vitamin D on liver function [6, 7]. Vitamin D deficiency is a risk factor for hepatocellular carcinoma [8] which inhibits the formation of collagen type I in hepatic satellite cells [9].

Circulating and tissue levels of transaminase enzymes including Alanine Aminotransferase (ALT), Aspartate Aminotransferase (AST), and Alkaline phosphatase (ALT), are used as sensitive indicators of liver function [10]. Epidemiological studies have shown an association between low serum levels of vitamin D and non-alcoholic fatty liver disease $[11,12]$. In addition, vitamin D deficiency is very common in patients with liver disease. Both cholestatic and non-cholestatic liver disease can lead to vitamin D deficiency [13]. Physical activity and exercise can reduce the fat of liver tissue in patients with non-alcoholic fatty liver, and the prevalence of fatty liver is lower in people with high physical activity [14]. However, low back pain itself can lead to inactivity and obesity, and obesity has a negative impact on the effectiveness of exercise therapy program for people with chronic nonspecific low back pain [18]. Exercise therapies, especially core stability exercises, are known to be the best method to control chronic nonspecific low back pain [1]. The present study aims to evaluate the serum transaminases activity in women with chronic low back pain following a core stability exercise program and vitamin D intake.

\section{Materials and Methods}

This clinical trial was conducted on 48 adult women with chronic low back pain selected by using a convenience sampling method. They randomly divided into four groups of Control, Supplementation, Exercise, and Exercise+Supplementation. The last two exercise groups performed 8 weeks of core stability exercises. The exercise protocol includes six movements of lower abdominal hollowing, supine, bridging, quadruped, dead bug and plank with different intensities, gradually increased to a higher level after each person reached a steady state at one level. The Supplementation and Exercise+Supplementation groups received 50,000 IU/week vitamin $\mathrm{D}$, while the control group consumed oral paraffin per week. At baseline, the subjects' pain was measured using the Visual Analog Scale (VAS). The levels of 25-hydroxyvitamin D, ALT, AST and ALP were measured before and after the interventions. Data were analyzed by paired t-test and ANOVA considering a significance level of $\mathrm{P}<0.05$.

\section{Results}

The demographical characteristics, pain intensity and vitamin D status of the study groups are presented in Table 1 . Based on the results, the vitamin D level in $74.26 \%$ of the subjects was $<20 \mathrm{ng} / \mathrm{mL}$, and in $25.64 \%$ it was $20-30 \mathrm{ng} / \mathrm{mL}$.

Eight weeks of core stability exercises, vitamin D intake and the combined intervention caused a significant reduction in AST, ALT and ALP activities. Combination of exercise and supplementation induced more reduction in the AST and ALP activities compared to other two groups received exercise and supplementation alone; the decrease in ALT activity in the combined group was higher than in the exercise group (Table 2).

\section{Conclusion}

In this study, 8 weeks of core stability exercises, vitamin D intake, and combined exercise and vitamin D supplementation reduced the AST, ALT, and ALP activities in women with low back pain who had vitamin D deficiency. The effect of combined intervention on reducing the activity of AST and ALP enzymes was higher compared to other two groups received exercise and supplementation alone, and its effect on reducing the activity of ALT was higher compared to the exercise group. Vitamin D receptors are expressed in hepatic satellite cells and vitamin D has anti-proliferative

Table1. Demographical and clinical characteristics of the participants

\begin{tabular}{cccccc}
\hline \multirow{2}{*}{ Group } & \multicolumn{5}{c}{ Mean \pm SD } \\
\cline { 2 - 6 } & Height $(\mathbf{c m})$ & Weight $(\mathbf{k g})$ & Age (year) & Pain Level & 25-hydroxyvitamin D (ng/mL) \\
\hline Exercise & $167.50 \pm 9.28$ & $71.90 \pm 10.13$ & $36.60 \pm 5.44$ & $6.50 \pm 1.27$ & $12.30 \pm 6.15$ \\
Vitamin D & $161.70 \pm 7.30$ & $66.00 \pm 8.70$ & $35.50 \pm 6.79$ & $5.80 \pm 1.62$ & $13.60 \pm 6.19$ \\
Combined & $166.10 \pm 8.91$ & $68.00 \pm 6.20$ & $39.30 \pm 3.68$ & $7.00 \pm 1.05$ & $13.10 \pm 6.50$ \\
Control & $161.77 \pm 5.31$ & $67.11 \pm 7.90$ & $34.58 \pm 5.50$ & $6.22 \pm 1.39$ & $12.55 \pm 6.24$ \\
\hline
\end{tabular}


Table 2. Comparison of changes in enzyme levels at baseline and 8 weeks after intervention

\begin{tabular}{|c|c|c|c|c|c|}
\hline \multirow{2}{*}{ Variables } & \multirow{2}{*}{ Groups } & \multicolumn{3}{|c|}{ Mean $\pm S D$} & \multirow{2}{*}{$\mathbf{P}^{*}$} \\
\hline & & Pre-test & Post-test & Changes (\%) & \\
\hline \multirow{4}{*}{ AST (U/L) } & Exercise & $25.40 \pm 5.52$ & $20.90 \pm 4.15$ & $-16.97 \pm 7.40^{\#}$ & $<0.001$ \\
\hline & Vitamin D & $24.30 \pm 4.71$ & $20.40 \pm 3.44$ & $-15.44 \pm 5.53^{\#}$ & $<0.001$ \\
\hline & Combined & $24.10 \pm 5.61$ & $17.50 \pm 2.59$ & $-25.81 \pm 9.17^{\# \mp}$ & $<0.001$ \\
\hline & Control & $24.11 \pm 3.44$ & $23.83 \pm 3.05$ & $0.89 \pm 3.84$ & 0.366 \\
\hline \multirow{4}{*}{$\operatorname{ALT}(\mathrm{U} / \mathrm{L})$} & Exercise & $18.40 \pm 4.27$ & $16.5 \pm 3.79$ & $-12.03 \pm 7.40^{\#}$ & 0.003 \\
\hline & Vitamin D & $20.00 \pm 5.08$ & $16.70 \pm 3.89$ & $-15.99 \pm 7.76^{\#}$ & 0.001 \\
\hline & Combined & $18.40 \pm 3.17$ & $14.20 \pm 2.09$ & $-22.32 \pm 6.60^{\# \pm \&}$ & $<0.001$ \\
\hline & Control & $18.89 \pm 3.89$ & $18.97 \pm 3.72$ & $0.63 \pm 2.90$ & 0.680 \\
\hline \multirow{4}{*}{$\operatorname{ALP}(U / L)$} & Exercise & $128.40 \pm 21.20$ & $117.20 \pm 18.73$ & $-8.63 \pm 5.25^{\#}$ & $<0.001$ \\
\hline & Vitamin D & $125.60 \pm 18.43$ & $118.00 \pm 15.71$ & $-5.85 \pm 2.63^{\#}$ & $<0.001$ \\
\hline & Combined & $126.00 \pm 20.94$ & $107.60 \pm 17.17$ & $-14.35 \pm 2.39^{\# 1 \&}$ & $<0.001$ \\
\hline & Control & $127.33 \pm 19.96$ & $127.16 \pm 21.27$ & $-0.15 \pm 1.18$ & 0.747 \\
\hline
\end{tabular}

*Paired t-test; " Significant difference compared to control group; ${ }^{\text {ES}}$ Significant difference compared to exercise group; ${ }^{\&}$ Significant difference compared to supplementation group

and anti-fibrogenic properties on these cells by inhibiting the Transforming Growth Factor- $\beta$ (TGF- $\beta$ )/SMAD pathway, which is one of the strongest anti-fibrogenic pathways in the liver. Vitamin D can also suppress the expression of collagen types I and III by inhibiting the activity of TGF- $\beta$ signaling pathway mediated by hepatocyte cells [28].

Exercise can improve steatosis through hepatic lipid metabolism by increasing the metabolism of fatty acids and hepatic lipids. Exercise increases oxidation of non-esterified fatty acids and reduces hepatic glucose production by activating hepatic and intramuscular Adenosine Monophosphateactivated Protein Kinase (AMPK) [15]. In addition, AMPK suppresses the proliferation of hepatic satellite cells [32].

It seems that core stability exercises, vitamin D intake, and combination of exercise and vitamin D supplementation may improve liver function in women with chronic low back pain by reducing liver enzymes activities. The combined intervention had greater effectiveness in improving liver function.

\section{Ethical Considerations}

\section{Compliance with ethical guidelines}

All procedures in this study were according to the guidelines of Islamic Azad University of Qaemshahr Branch by observing the ethical points, and maintaining the safety and health of the subjects. A written informed consent was signed by all participants. They were free to leave the study at any time. This paper was approval by Ethics Committee of the Islamic Azad University of Babol Branch (Code: IR.IAU. BABOL.REC.1398.086).

\section{Funding}

This study was extracted from the MA. thesis of first author, Department of Physical Education, Qaemshahr Branch, Islamic Azad University, Qaemshahr.

\section{Authors' contributions}

All authors have equally contributed to the preparation of this article.

\section{Conflicts of interest}

The authors declared no conflict of interest. 


\title{
مطالعه فعاليت ترانس آمينازها در زنان مبتلا به كمردرد متعاقب تمرينات ثباتدهنده مركزى و \\ Dصرف ويتامين Dماليت ترأس
}

سيد جواد هاشمى سنكتراشانى' [ـ، "معصومه حبيبيان' هـ سيد جعفر موسوى' (ه)

ا. كروه تربيت بدنى، واحد قائمشهر، دانشعاه آزاد اسلامى، قائمشهرءايران.

\begin{abstract}
ميكيد
إزمينه نقص يا سطوح ناكافى ويثامين D در بيماران كبدى بسيار شايع است و ارتباط نزديكى بادردهاى اسكلتى عضلانى از جمله كمردرد

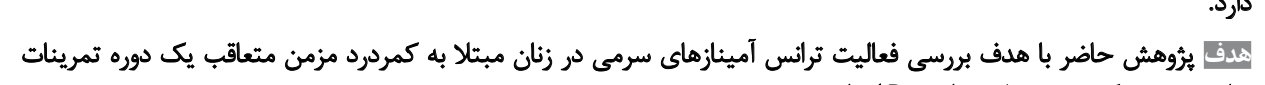

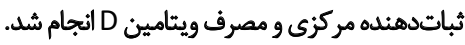

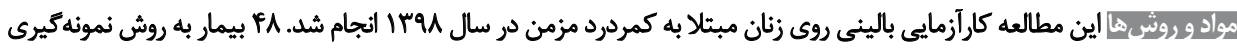

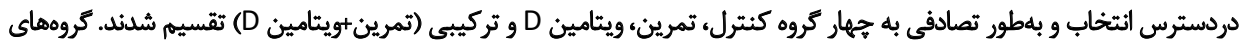

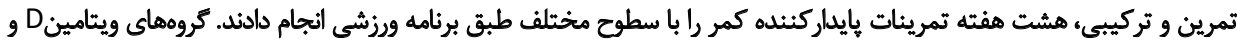

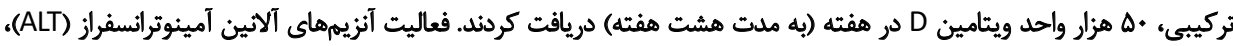

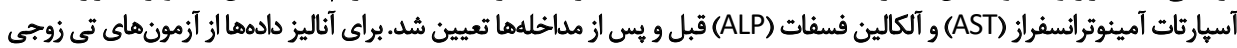

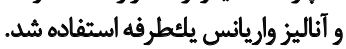

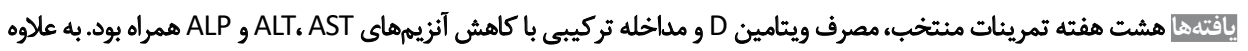

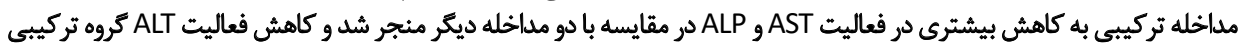

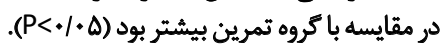

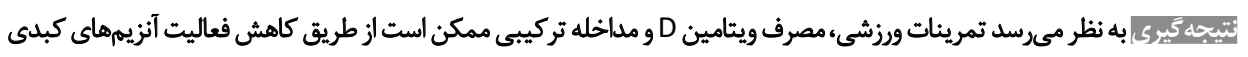

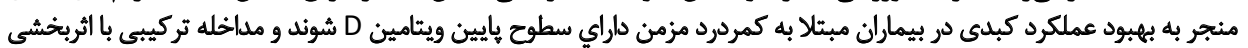

تاريخ دريافت: ا• تير 99

تاريخ يذيرش: T. مهر 99

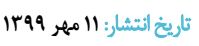

به كمردرد مزمن، علت خاصى براي درد دارند [1]] ييش از اين إئ

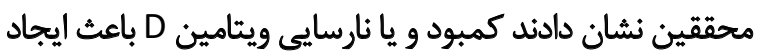

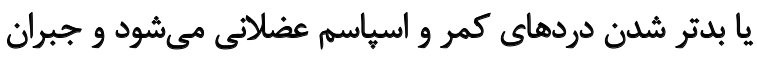

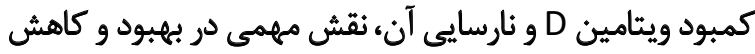

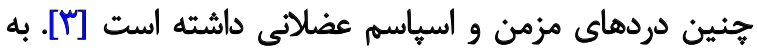

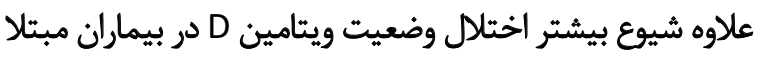

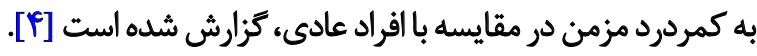
بيش از • ج درصد ويتامين D در بافت يوست انسان، تحت

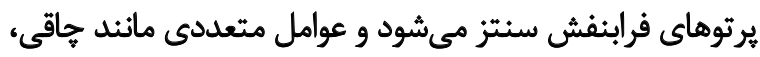

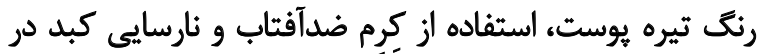

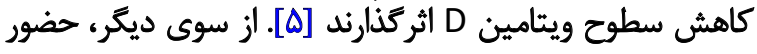

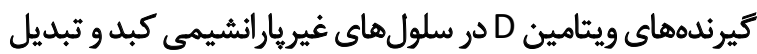

\section{مقدمه}

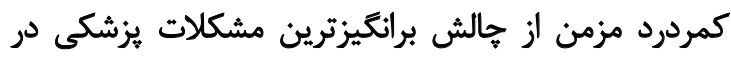

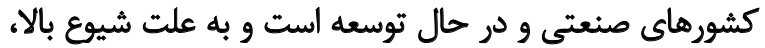

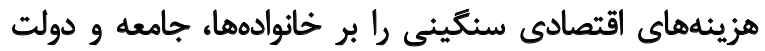

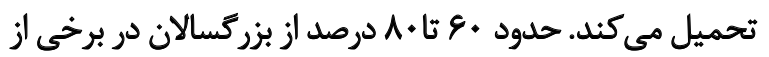

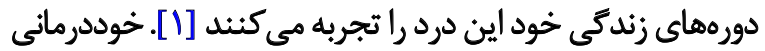

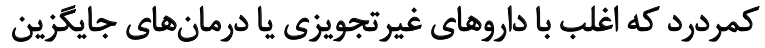

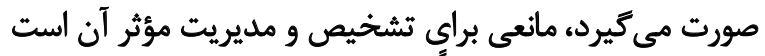

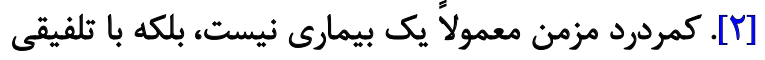

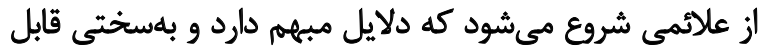

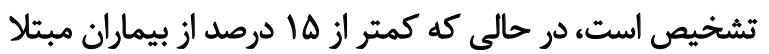

$$
\begin{aligned}
& \text { * مويسئده مسئول: } \\
& \text { معصومه حبيبيان }
\end{aligned}
$$

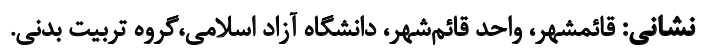

$$
\begin{aligned}
& \text { تلفي: } \\
& \text { راياثامه: habibian_m@yahoo.com }
\end{aligned}
$$




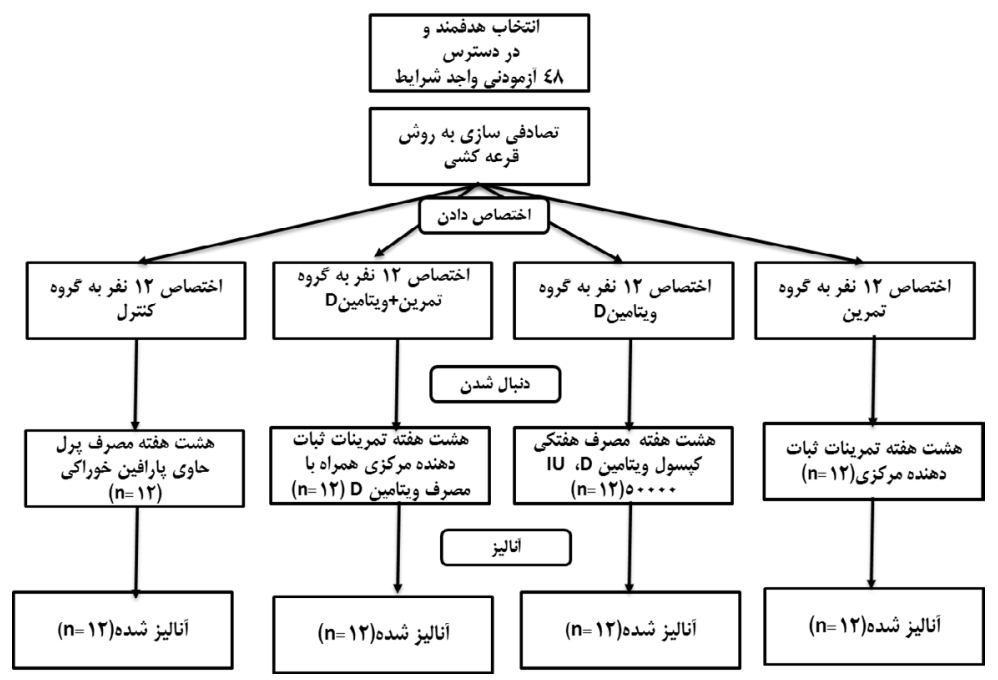

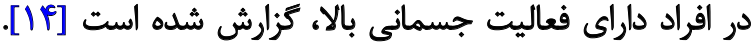

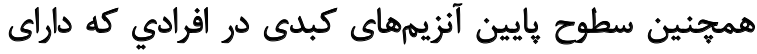

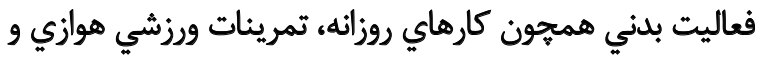

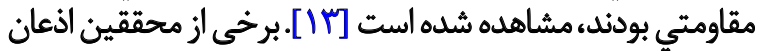

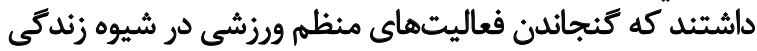

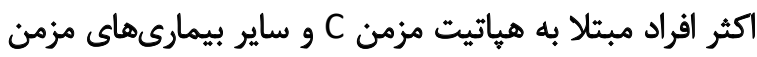

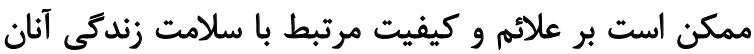

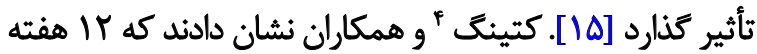

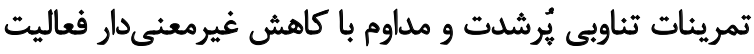

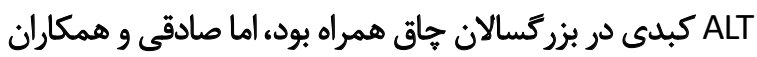

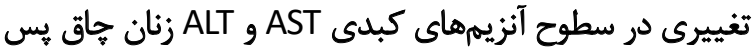

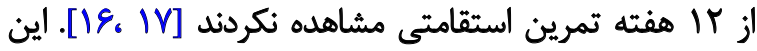

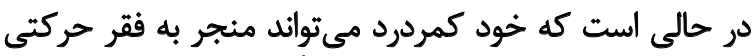

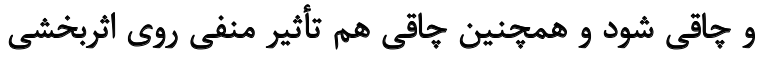

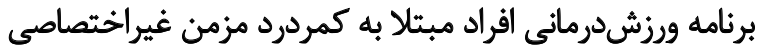

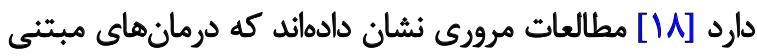

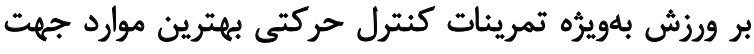

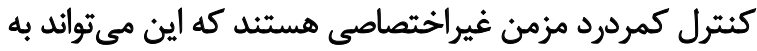

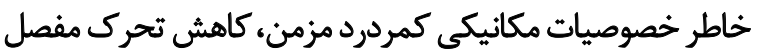

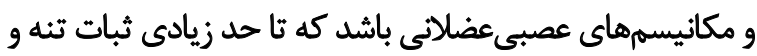

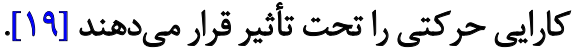

بيش از اين، شيوع زياد كمبود ويتامين D در كشور ايران

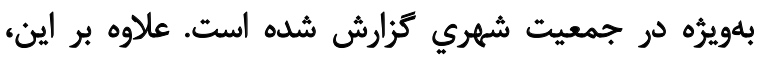

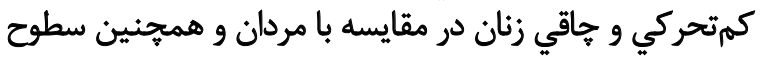

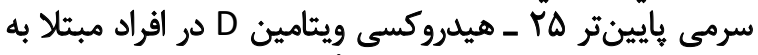

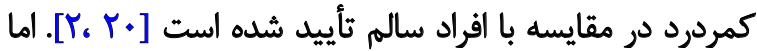

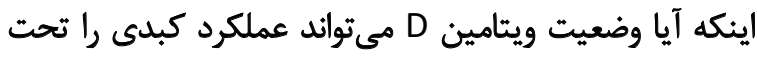

\section{Keating}

موضعى ويتامين D جذبشده به شكل فعال آن در بافتهاي

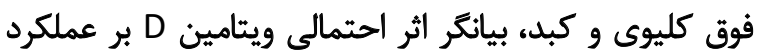

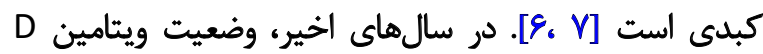

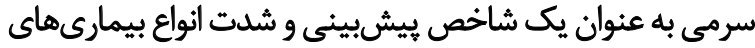

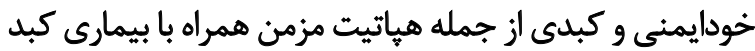

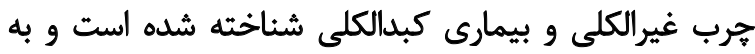

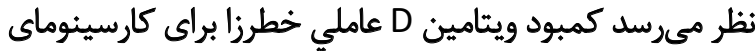

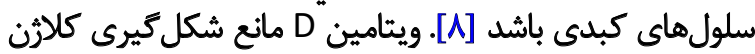

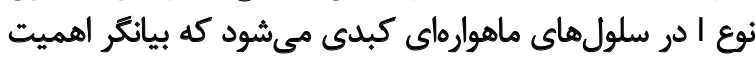

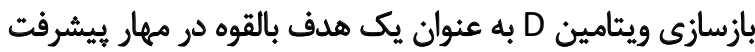

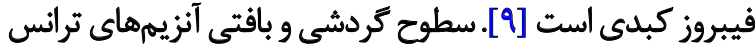

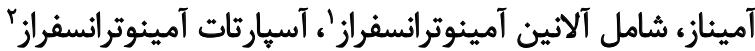

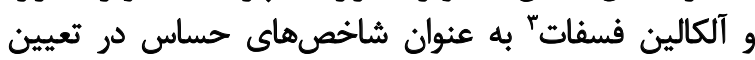

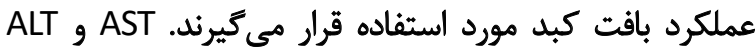

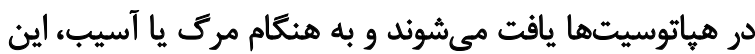

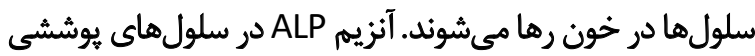

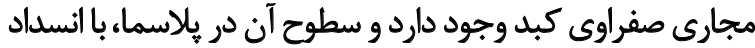

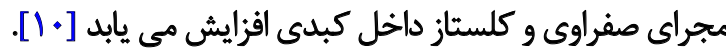

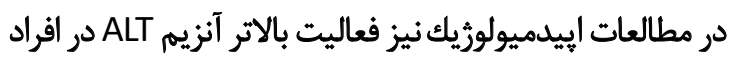

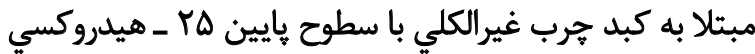

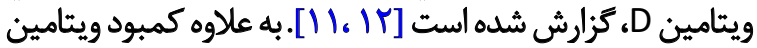

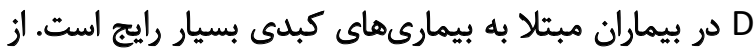

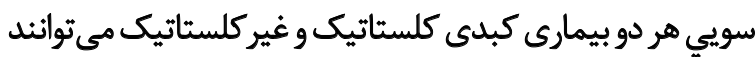

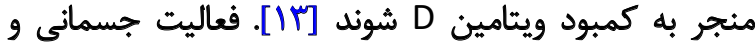

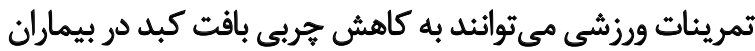

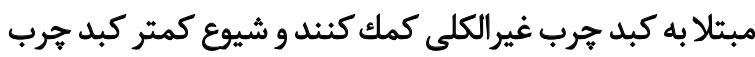

3. Alkaline Phosphatase (ALP) 
جدول ا. نحوه اجراى تمرينات ثباتدهنده مركزى و مراحل آن

\begin{tabular}{|c|c|c|}
\hline 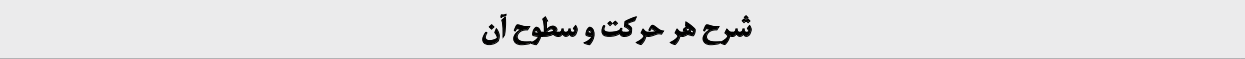 & \multicolumn{2}{|c|}{ نام حركت } \\
\hline 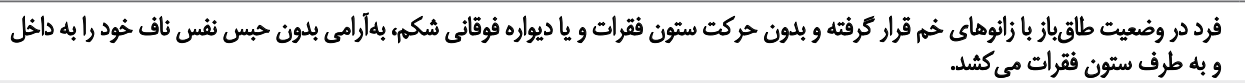 & \multicolumn{2}{|c|}{ 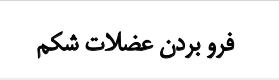 } \\
\hline 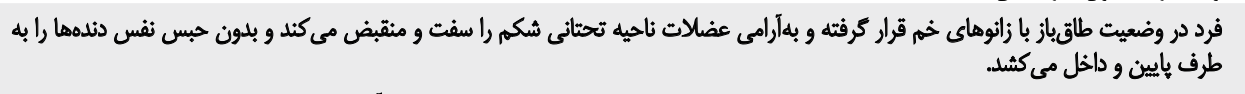 & 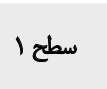 & \multirow{4}{*}{ 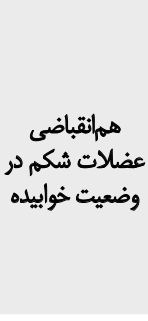 } \\
\hline 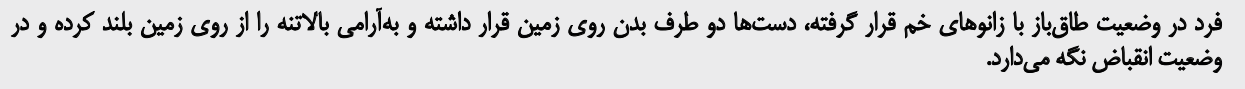 & 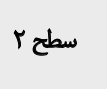 & \\
\hline انقباض در وضعه ميت طارد. باز با زانوهاى خم قرار كرقته و با نزديك كردن دستهاى صافشده به زانو، بالاتثه را از روى زمين بلند كرده و در وضعيت & 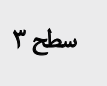 & \\
\hline 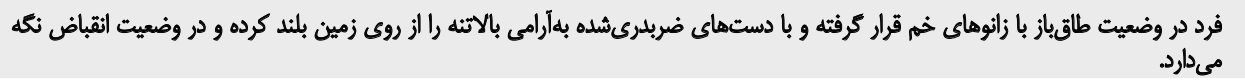 & سطح f & \\
\hline 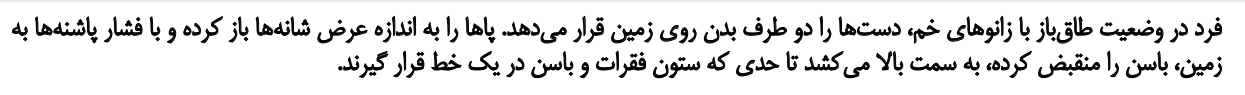 & سطع 1 & \multirow{4}{*}{ 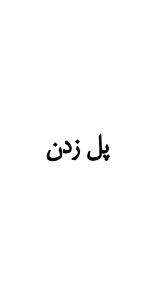 } \\
\hline أزمودنى در هنكام يل زدن دج يكى از هاها را اندكى از سطح زمين بالاتر نكه مي دارد (با تكرار براى ياى ديكر). & 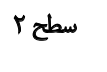 & \\
\hline أزمودنى در هنكام يل زدن يكى از باها را با زانوى خم از سطح زمين بالاتر نكه مى دارد (با تكرال براى هاي ديكر). & سطح & \\
\hline أزمودنى در هنكام يل زدن يكى از باها را با زانوى صاف تا امثداد ستون فقرات و باسن بالا مى كشد (با تكرار براى بايى ديكر). & سطح & \\
\hline 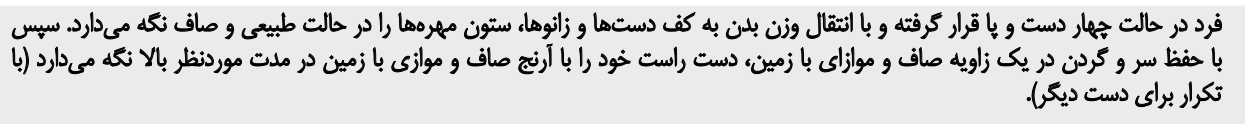 & سطع 1 & \multirow{5}{*}{ 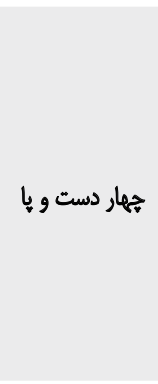 } \\
\hline در اين سطح فرد ياى راست خود را با زانوى صاف، در امتداد ستون مهرهها و موازى با زمين در مدت موردنظر بالا نكه مى دارد (با تكرار براى باى ديكى). & سطح r M & \\
\hline در اين سطح فرد باى راست و دست جهب خود را در مدت موردنظر بالا نكه مى دارد (با تكرار برايى دست و ياى ديكر). & سطع r & \\
\hline در اين سطح فرد بلدون آن كه زاويه مهرههاى كمر تغييرى كثلد بهآرامى لكن خود رادر ملت موردنظر به جلو مى كشد. & 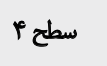 & \\
\hline در اين سطع فرد بلدون أنكه زاويه مهرههاى كمر تفييرى كثل، بهأرامى لكن خود را در ملت موردنظر عقب مى كشلد. & سطع ه & \\
\hline 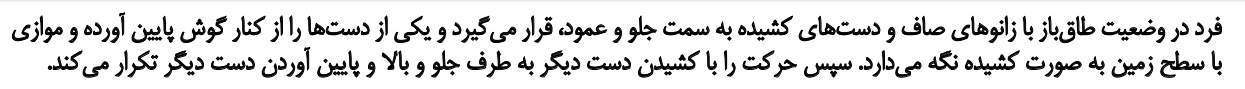 & سطع 1 & \multirow{4}{*}{ 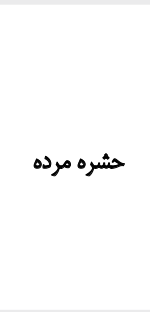 } \\
\hline 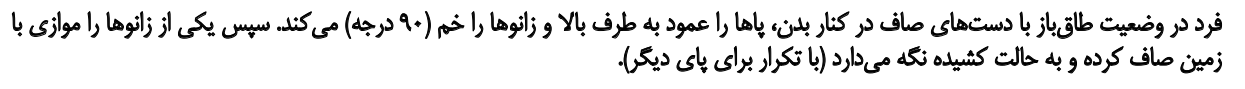 & 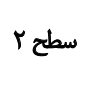 & \\
\hline 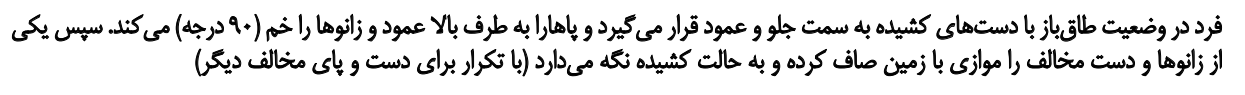 & 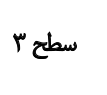 & \\
\hline أزمودنى ها حركت سطح قبل را با بستن مقاومت به باها انجام مىدهند. & سطح P & \\
\hline 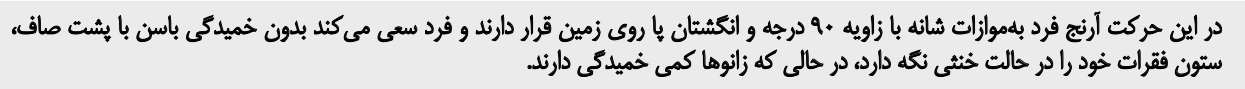 & سطع 1 & \multirow{4}{*}{ يلانك } \\
\hline 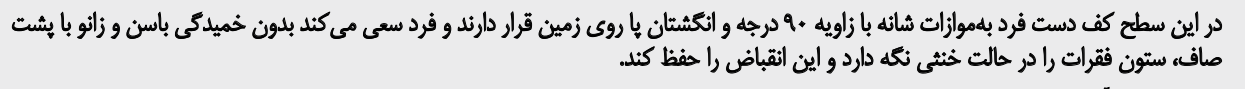 & سطع r ( la & \\
\hline 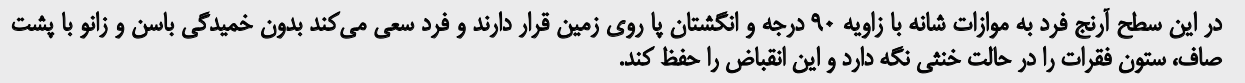 & سطح r & \\
\hline براى ياند ديكي). سطح قبل است، ولى فرد سعى مى كند يكى از ياهاى خود را تا حد امكان بدون خم كردن يشت، بالاتر از سطع زمين نكه دارد (با تكرار & 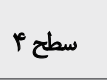 & \\
\hline
\end{tabular}

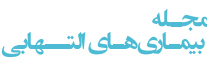

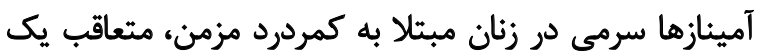

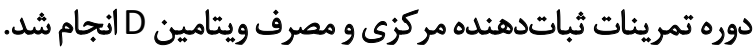

$$
\text { 10. }
$$

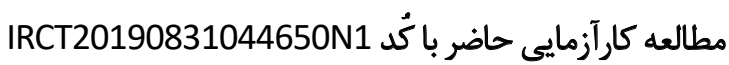

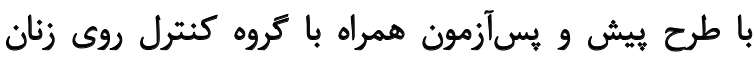

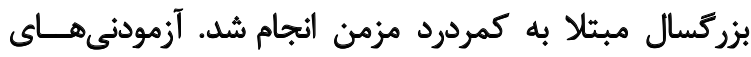

تأثير قرار دهد، مشخص نيست. اين در حالي است كه امروزه

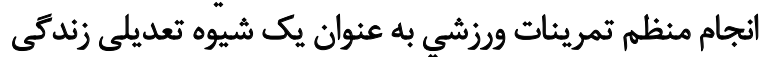

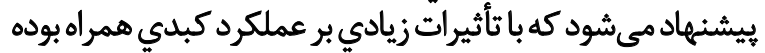

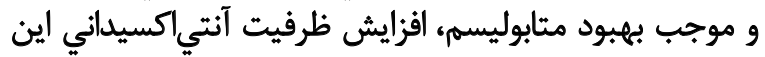

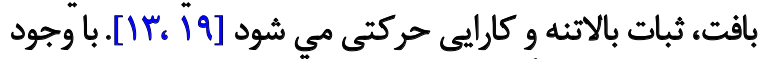

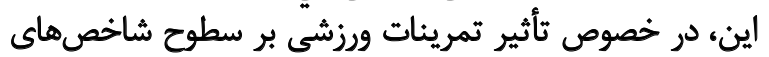

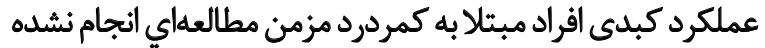

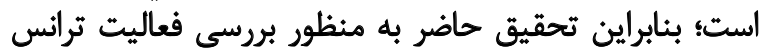


جدول r. ميانكين و انحراف استاندارد شاخص هاي آنترويومترى و سطوح فا-هيدروكسى ويتامين D آزمودنى هاى تحقيق

\begin{tabular}{|c|c|c|c|c|c|c|}
\hline \multicolumn{6}{|c|}{ ميانكين土|نحراف استاندارد } & \multirow{2}{*}{ تروه } \\
\hline 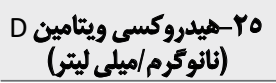 & ميزان درد & (كيلوترم/ مترمربع) BMI & سن (سال) & وزن (كيلوكّرم) & قد (سانتى متر) & \\
\hline $1 r / 8 \pm+r \cdot 11 \theta$ & $e / \pm \Delta \cdot / R$ & $r \Delta / T \pm \Delta F / . r$ & $r e / \Delta \pm 8 \cdot / \mu f$ & $m / 1 \cdot \pm q \cdot / l r$ & $\mid E N / 9 \pm \Delta \cdot / r \Lambda$ & تمرين \\
\hline $1 \% / F \pm \varepsilon . / 19$ & $\Delta / / \pm \Lambda \cdot / R T$ & $r \Delta / r \pm m T / g q$ & $r \Delta / q \pm \Delta \cdot / M q$ & $g \& / A \pm \ldots / N$ & $|F| / Y \pm Y_{*} / T^{\prime}$ & ويتامينD \\
\hline$|r| e \pm 1 \cdot / \Delta$ & $V / \pm \pm \cdot \cdot / \cdot \Delta$ & $r \Delta / 1 \pm \Delta S M$ & $m q / \pm m+18 \lambda$ & ENEI+* K. & $|\Leftrightarrow| A \pm \pm 1 . / 9 \mid$ & توكييى \\
\hline $\mid T / \& \pm \Delta \Delta / T \varphi$ & 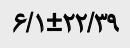 & $r \Delta / \Delta \pm \Delta Y / \Delta$. & $\operatorname{Me} / \Delta \pm \Delta N \Delta$. & $E N / N \pm 11 / 9$. & $|\& V / \Delta \pm W / M|$ & كثترل \\
\hline \% AF & ITM & .NEq & v/rat & ./9M & $1 / \% A^{\circ}$ & F ارزش F \\
\hline.$/ Q 81$ & Tr &.$/ 918$ & . & . & . & $\mathrm{P}^{*}$ \\
\hline
\end{tabular}

جدول با. تعداد آزمودنى هاي كروه هاى تحقيق در سطوح مختلف ويتامين D

\begin{tabular}{|c|c|c|c|}
\hline (بيشتر از +"انانوحترم/ميلى ليتر) & 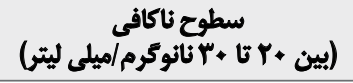 & (كمتر از +r نانوكرم/ميلى ليتر) & تروه \\
\hline - & 9 & 0 & تمرين \\
\hline . & 1. & $r$ & ويتامين D \\
\hline . & A & $r$ & تركييى \\
\hline . & 9 & $r$ & كنترل \\
\hline & عَ" نفر & זا نفر & كل \\
\hline
\end{tabular}

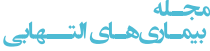

سيس به صورت تصادفى به روش قرعه كشي به جهار تروين

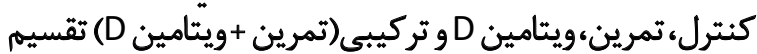

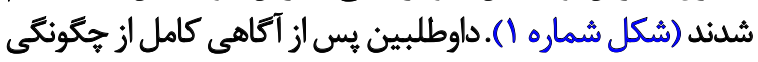

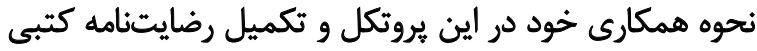

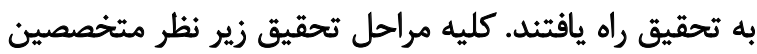

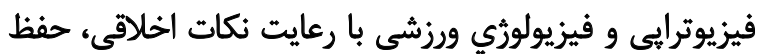
ايمنى و سلامت آزمودنى فها انجام شد.

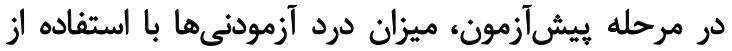

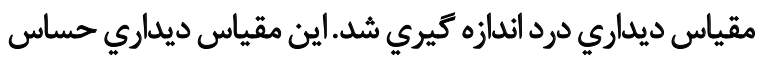

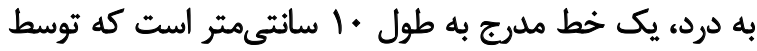

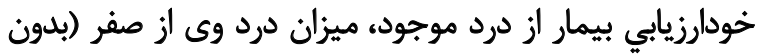

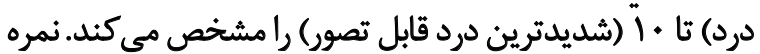

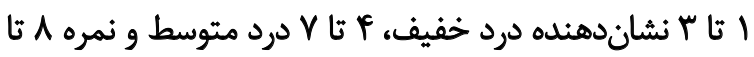
• أشاندهنده درد شديد بوده است [1/]].

يروتكل تمرينى آزمودنى هاى كروههاى تمرين و تركيبى شامل

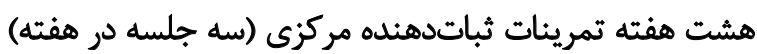

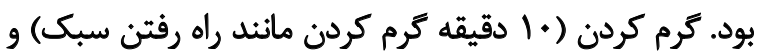
سرد كردن به ترثيب در ابتدا و انتهاى هر كرد جلسه ماند تمرينى رفتي انجام

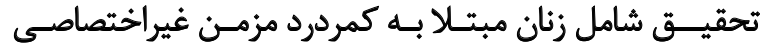

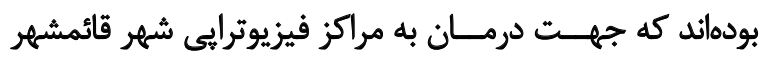

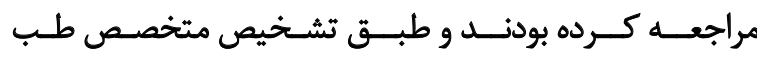

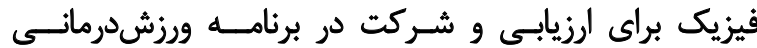

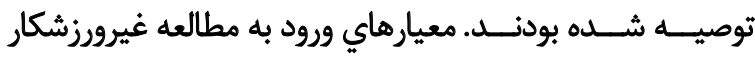

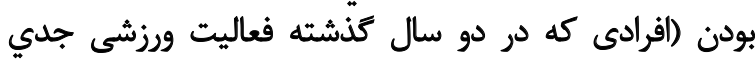

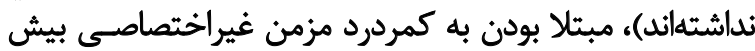

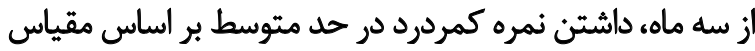

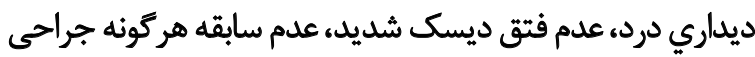

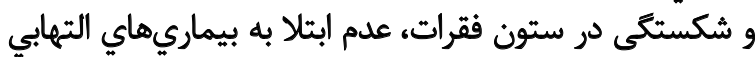

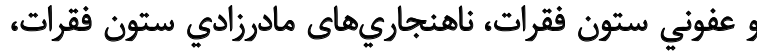

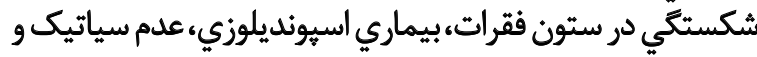

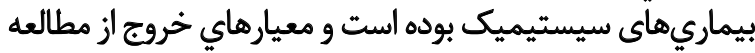

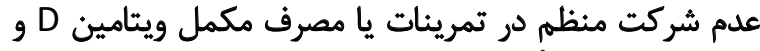

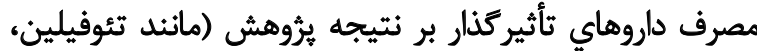

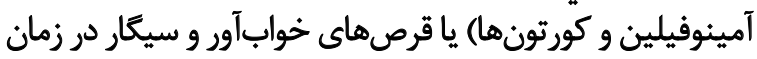

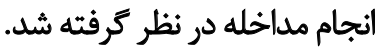
ابتدا fl آزمودنى به طور دردسترس و هدفمند انتخاب شدند. 


\begin{tabular}{|c|c|c|c|c|c|}
\hline \multirow{2}{*}{$\mathrm{P}^{*}$} & \multirow{2}{*}{ درصد تغييرات (\%) } & \multicolumn{2}{|c|}{ مياتكين 玉|نحراف استاندارد } & \multirow{2}{*}{ كروه ها } & \multirow{2}{*}{ مثغير } \\
\hline & & يس آزمون & يبيش أزمون & & \\
\hline$<\cdot 1 * \bullet$ & $-1 \varepsilon / V \pm 9 V / \%$ *\# & $r \cdot / r \pm q \cdot / 1 \Delta$ & $r \Delta / \Delta \pm+F / \Delta r$ & تمرين & \\
\hline$<+1++1$ & $-1 \Delta / \Delta \pm \mu \tau / \Delta T^{\#}$ & $r+/ r \pm r+/ F r$ & $r f / r \pm r+/ r)$ & ويثامين D & فعاليت AST (واحد) \\
\hline$<+1++1$ & $-r \Delta / q \pm A V / / Y^{\#}$ & $\mid \gamma / r \pm \Delta \cdot / \Delta q$ & $r f / \Delta \pm \mid+/ s)$ & تركيبى & ليتر) \\
\hline \multirow[t]{3}{*}{. } & 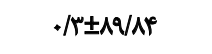 & $r r / r \pm \lambda r / \cdot \Delta$ & $r t / T \pm I I / R r$ & كنترل & \\
\hline & $F=* / \backslash \Delta V$ & $P=* / 9 Y \Delta$ & \multicolumn{3}{|c|}{ هقايسه بين كروهى مياتكين قعاليت AST در ييش أزمون } \\
\hline & $F=r / T / M I r$ & $\mathrm{P}<+/ .+1$ & \multicolumn{3}{|c|}{ مقايسه يين كورهى درصد تفييرات فعاليت AST } \\
\hline /.rr & $r / N \pm \cdot r / \psi^{*} * \#$ & $19 / \pi \pm \Delta \cdot / V^{\prime}$ & $W \Psi \pm F \cdot / Y Y$ & تمرين & \\
\hline $.1+.1$ & $-10 / V \pm 99 / / \% \#$ & $1 E / \% \pm Y \cdot / \wedge q$ & $r \cdot \mid \Delta \pm * . \cdot 1 \cdot 1$ & 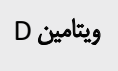 & فاليت ALT \\
\hline$<\cdot / \cdot \bullet$ & $-K Y / \& \pm T Y / \& \cdot 8 E \#$ & $1 F / r \pm r+1 . q$ & $W r \pm r+/ I Y$ & 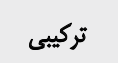 & (واحد/ليتر) \\
\hline \multirow[t]{3}{*}{.$/ 9 A}$. & $. / T \pm R / q$ & $W r \pm q V M$ & $W r \pm \wedge 9 / 19$ & 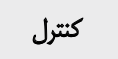 & \\
\hline & $\mathrm{F}=\star / \pi T \Lambda$ & $P=* / \Lambda+\Delta$ & \multicolumn{3}{|c|}{ مقايسه بين كروهي ميانكين فعاليت ALT در ييش آزمون } \\
\hline & $F=r+\mid \varepsilon+1$ & $\mathrm{P}<+/ *+1$ & \multicolumn{3}{|c|}{ مقايسه بين كروهي درصد تغييرات فعاليت ALT } \\
\hline$<+1++1$ & $-N \Delta \pm \Omega \Psi / T \Delta^{\#}$ & $\| V / M \pm \pm r+/{ }^{n}$ & $\mid r N T I \pm F \cdot / T$. & تمرين & \\
\hline$<+1++1$ & $-\Delta / T \pm \Lambda \Delta / \mathbb{R}^{\# \#}$ & $|W| \Delta \pm+\cdots / M$ & $\mid r \Delta / \Lambda \Delta \pm \varepsilon_{*} / T T$ & 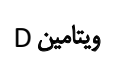 & فعاليت ALP (واحلـ/ \\
\hline$<\cdot 1 \cdot+1$ & 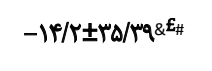 & 1. $V / / V \pm e_{*} / 1 Y$ & $\mid r E / T+ \pm * / 9 \varphi$ & تركييى & ليتّ) \\
\hline \multirow[t]{3}{*}{ MPr } & $-+/ 1 \pm 1 \Delta / 1 A$ & $\mid r V / T I \pm I E / T Y$ & $\mid r V / 9 \pm \pm \pi / 4$ & 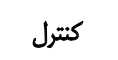 & \\
\hline & $F=* / \cdot r A$ & $\mathrm{P}=. / 99$. & \multicolumn{3}{|c|}{ مقايسه بين كروهى ميانكين فعاليت ALP در ييش آزمون } \\
\hline & $F=R T / 11 /$ & $\mathrm{P}<+/ 6+1$ & \multicolumn{3}{|c|}{ مقايسه بين كروهى درصد تغييرات فعاليت ALP } \\
\hline
\end{tabular}

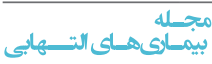

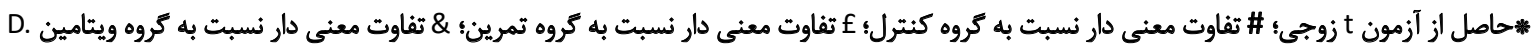

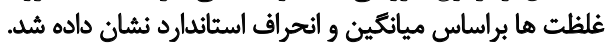

افزايسـ مدتزمان انقباض هـر حركت طراحى شــــ به طورى

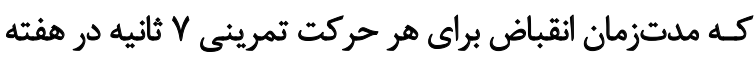

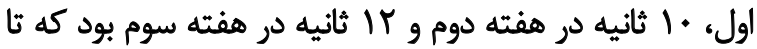

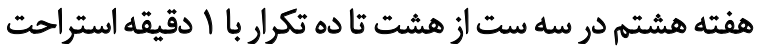

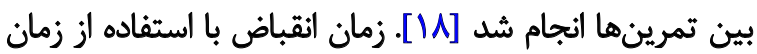

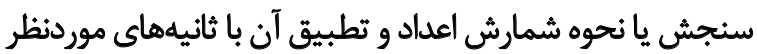
رعايت مىشد (جدول شماره ().

كروههاى ويتامين D و تركيبى (تمرين + ويتامين D) تيرل

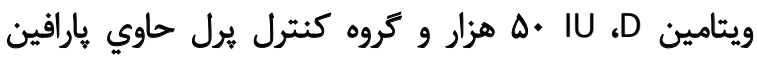

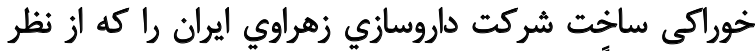

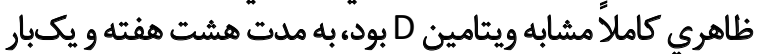

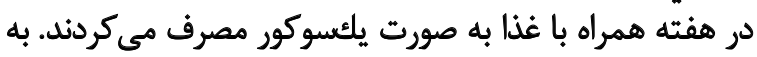

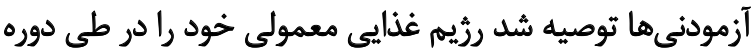

مىشد. برنامه اصلى تمرينى شامل شش دسته حركات فرو بردن

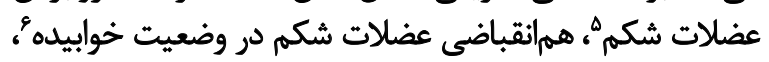

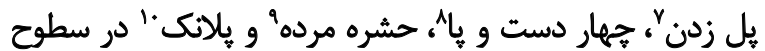

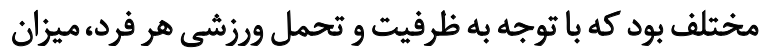

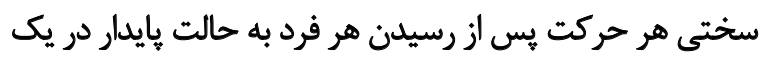

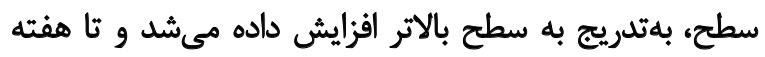

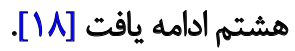

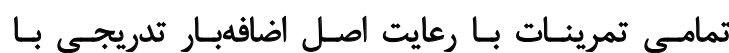

5. Lower abdominal hollowing

6. Supine

7. Briding

8. Quadriped

9. Dead bug

10. Plank 
جدوله. نتايج آزمون هاى تعقيبى ميانكين و درصد تغييرات آن در متغيرهاى تحقيق

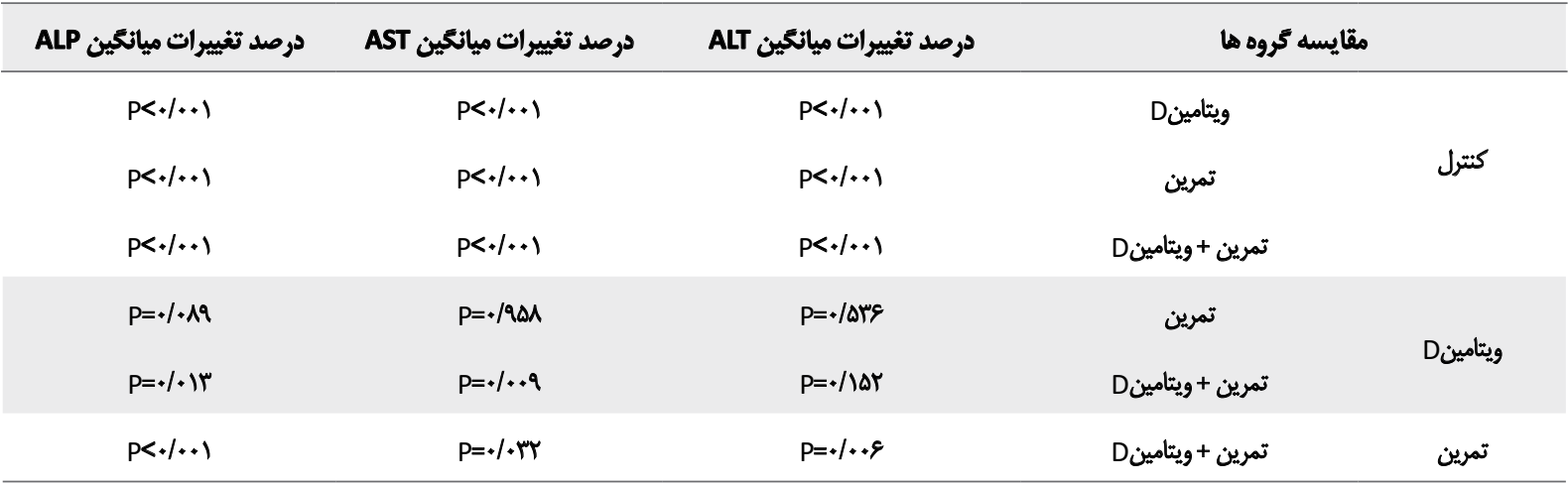

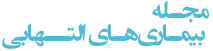

مكملسازى باويتامين D، تمرينات ثباتدهنده مركزى و و تركيبى

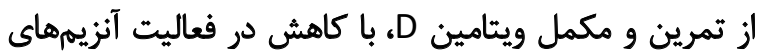

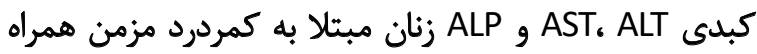

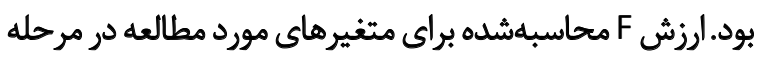

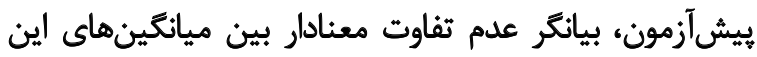

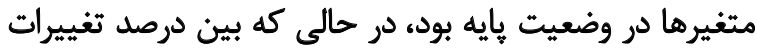

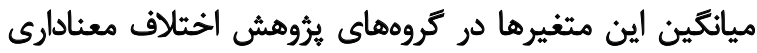

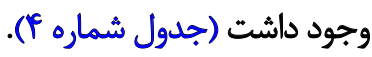

نتايج حاصل از مقايسه دوبهدو (آزمون تعقيبى) نشان داد كه

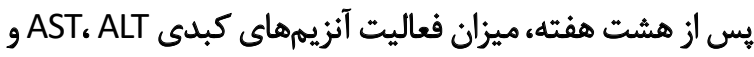

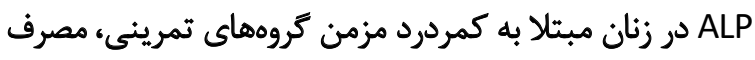

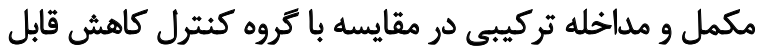

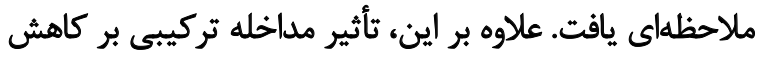

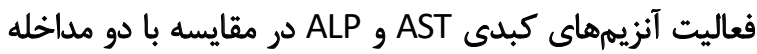

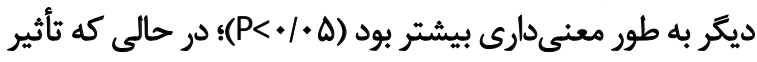

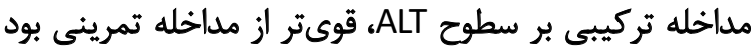

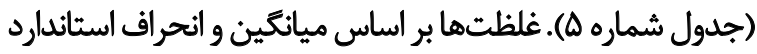
نشان داده شد.

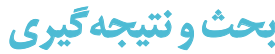

در تحقيق حاضر اثر هشت هفته تمرينات ثباتدهنده مركزى

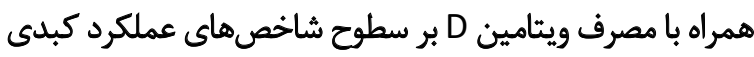

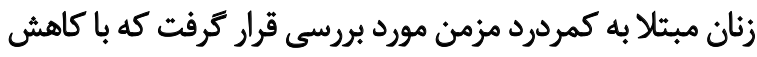

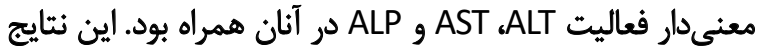

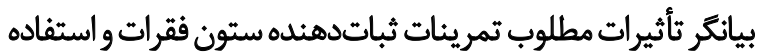

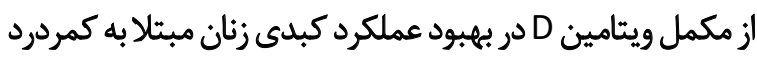

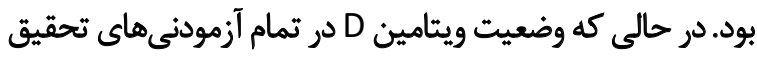

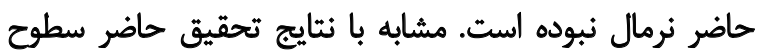

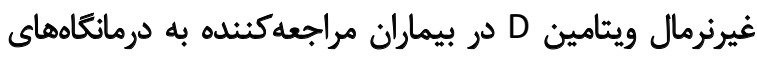

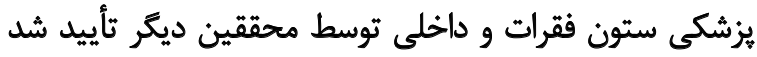

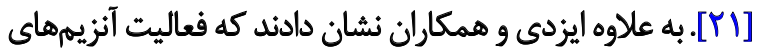

تحقيق (بهويثه در مراحل قبل از خون كيرى) رعايت كنيند.

مقادير DT _ ـ هيدروكسى ويتامين D با استفاده از روش الايزا (uroimmun, Luebeck, Germany)

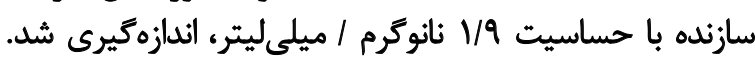
ميزان فعاليت آنزيمهاي كبدى به به روش آنزيماتيك و و با استفاده

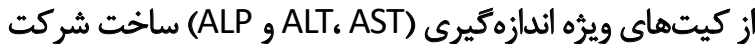

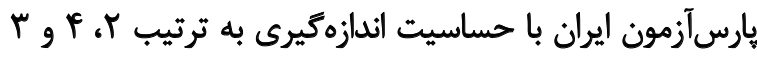

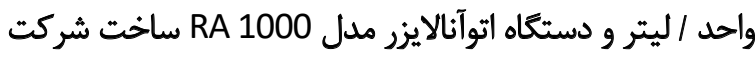

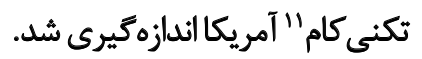

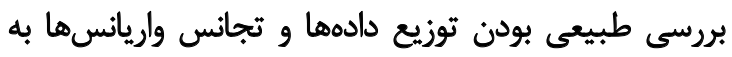

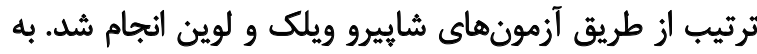

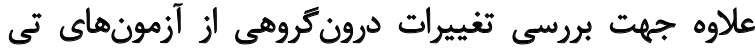

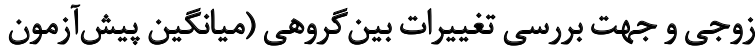

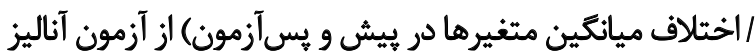

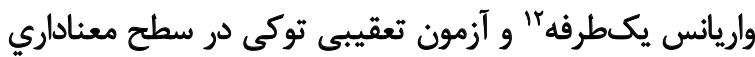

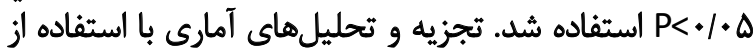

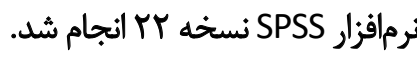

Lod

در جدول شماره Y شاخصهاى آنترويومترى آزمودنىها،

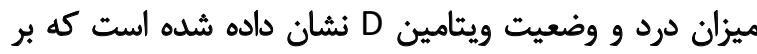

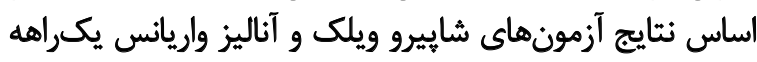
آزمودنى ها در وضعيت إيايه همسان بودهاند.

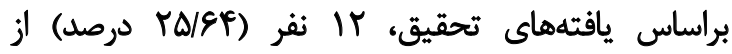

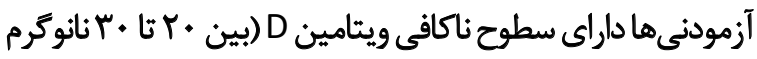

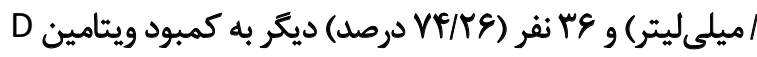

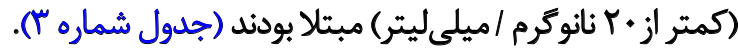
همجنين نتايج بررسى درون كروهى نشان داد كه هشت هفته 


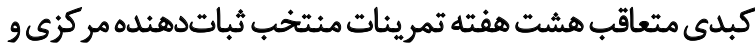

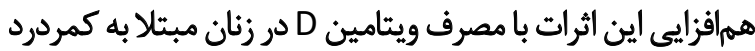

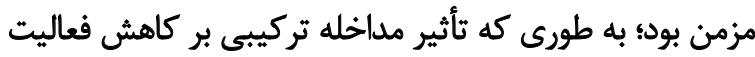

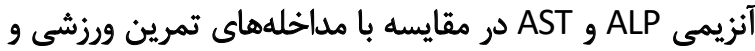

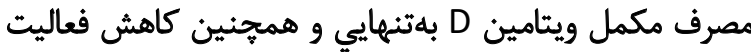

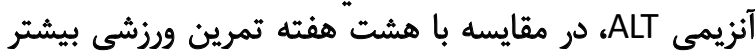

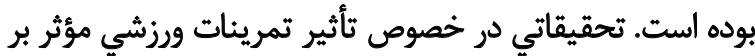

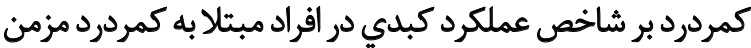

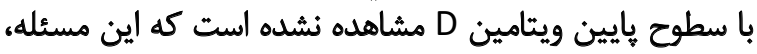

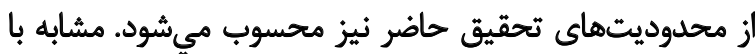

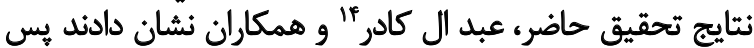

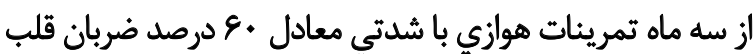

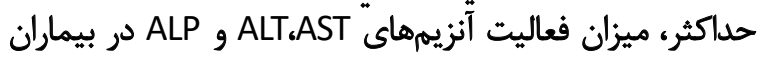

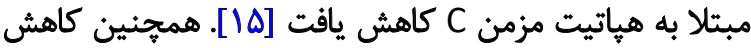

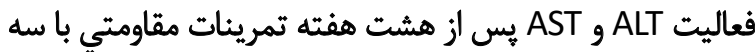

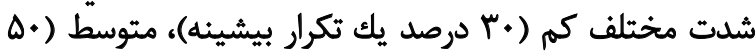

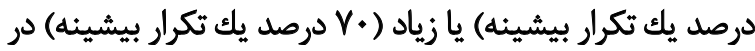

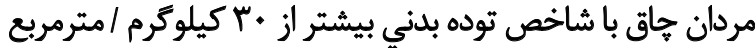

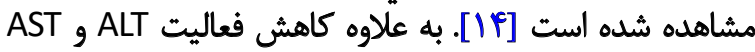

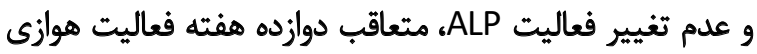

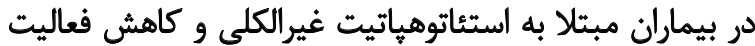

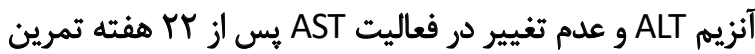

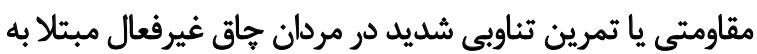

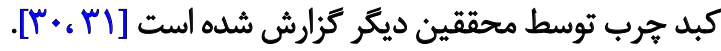

مكانيسم مستقيمى كه توسط آن فعاليت ورزشى مى تواند

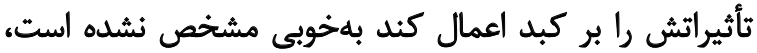

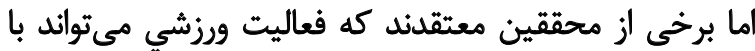

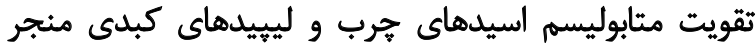

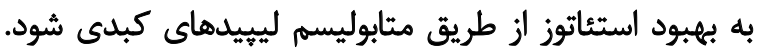

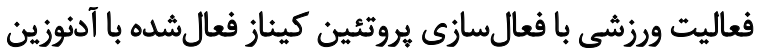

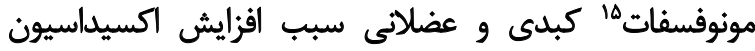

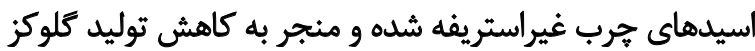

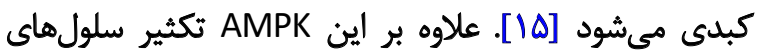

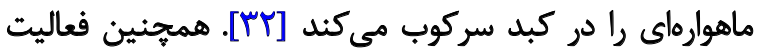

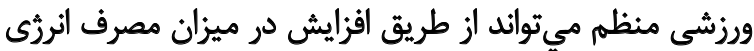

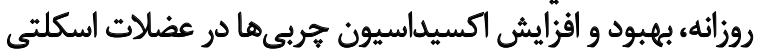

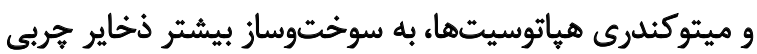

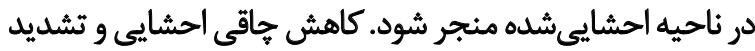

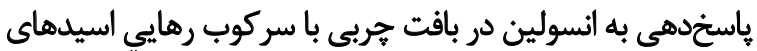

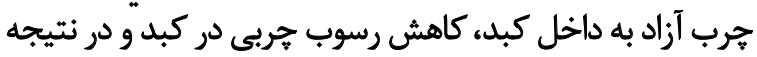

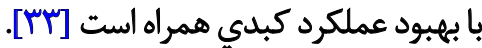

\section{Abd El-Kader}

15. Adenosine Monophosphate-activated Protein Kinase is an enzyme (AMPK)

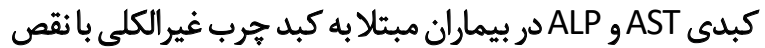

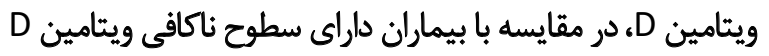

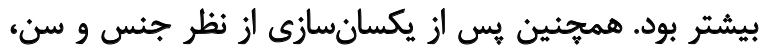

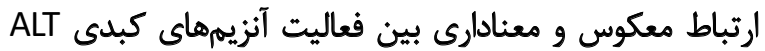

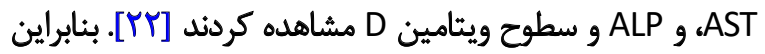

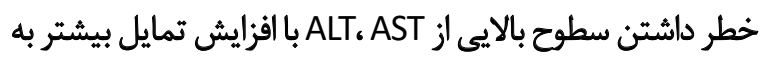

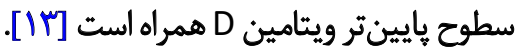

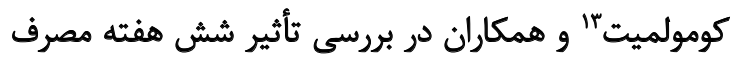

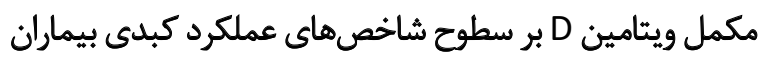

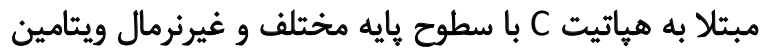

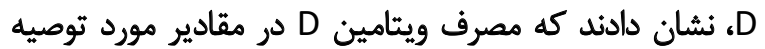

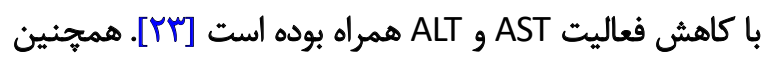

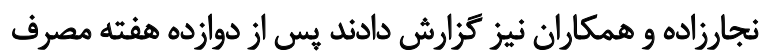

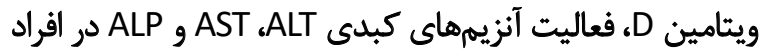

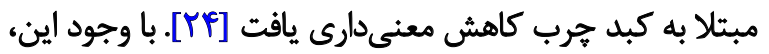

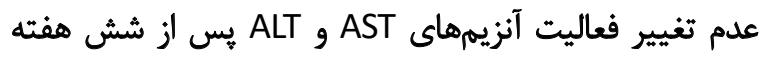

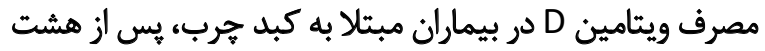

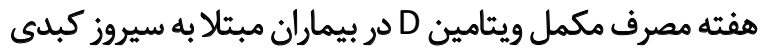

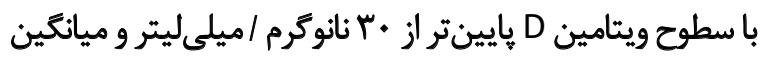

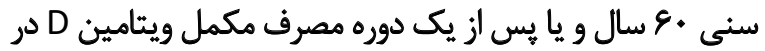

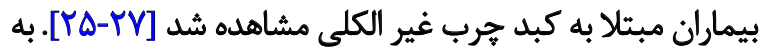

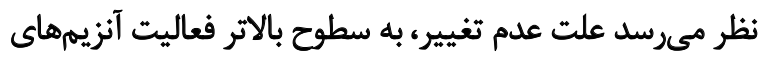

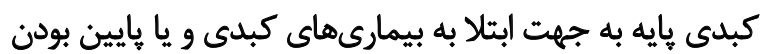

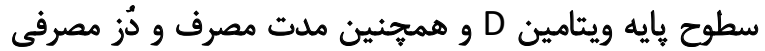

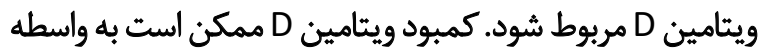

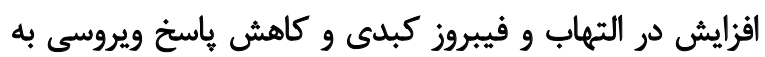

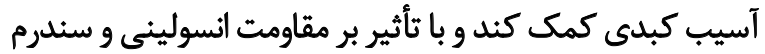

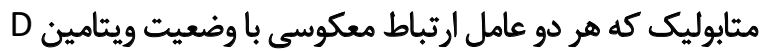

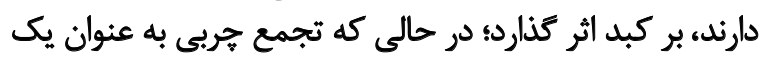

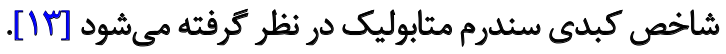
مكانيسمهاي تأثير ويتامين D بر بهبود عملكرد كبد كاملاًد مئرى

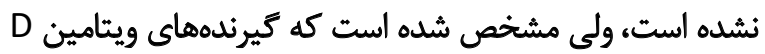

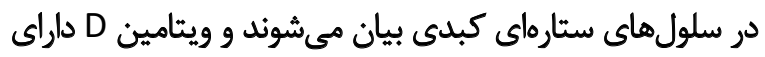

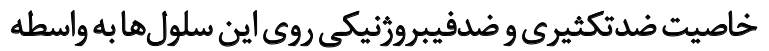

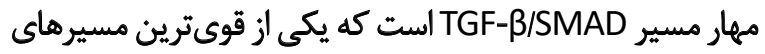

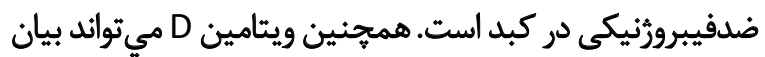

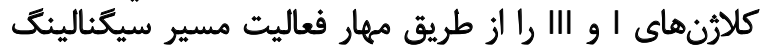

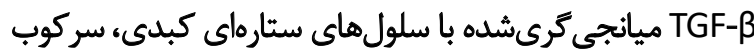

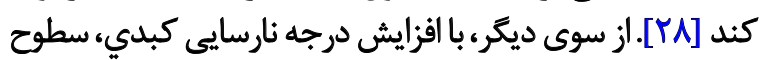

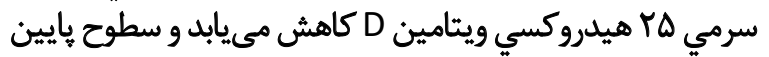

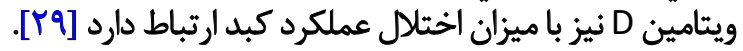
از جمله يافتههاى مهمم تحقيق حاضر، كاهش فعاليت آنزيمهاى

13. Komolmit 


\section{مشاركت ثويسند}

تمام نويسندكان در طراحي و اجراى همه بخش هاي يرونش

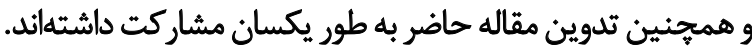

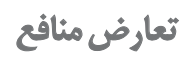

بنابر اظهار نويسندكان، هيج تعارض منافعى در اين مقاله وجود
از سوى ديكر فعاليتهاى ورزشي ممكن است به واسطه تنظيم

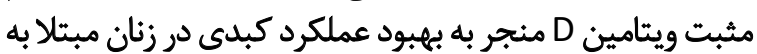

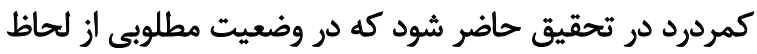

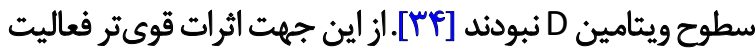

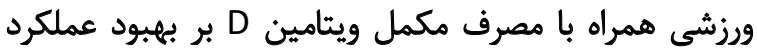

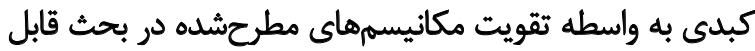

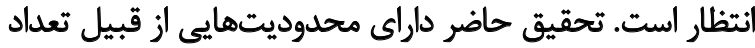

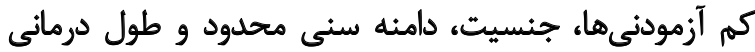

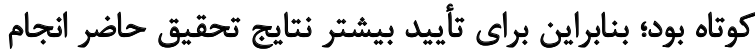

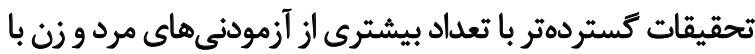

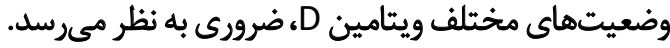
بر اساس يافتهها، زنان مبتلا به كمردرد در تحقيق حاضر

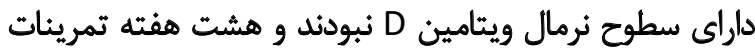

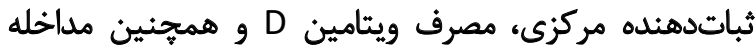

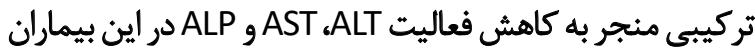

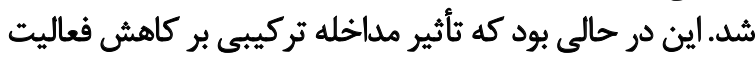

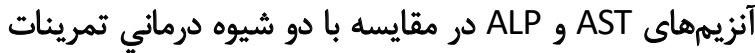

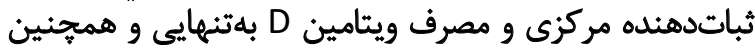

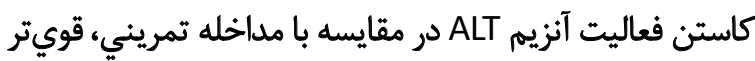

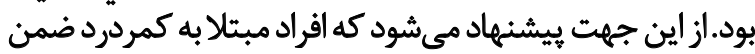

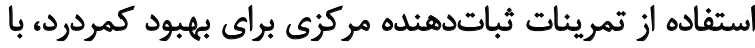

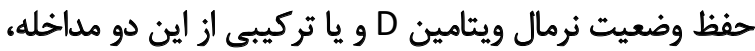
عملكرد كبدى خود را توسعه بخشند.

مالاحظات الخالاقي

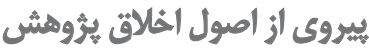

IR.IAU.BABOL. اين مطالعه داراى كُد اخلاق به شماره

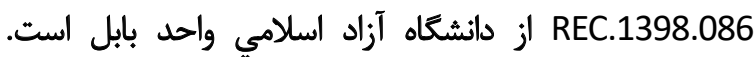

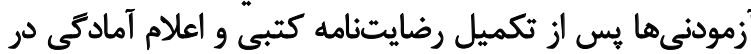

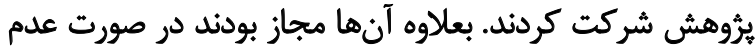

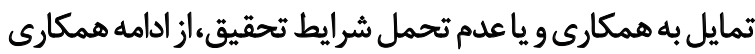

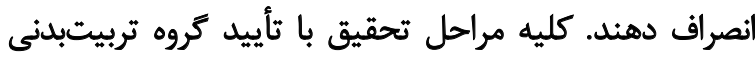

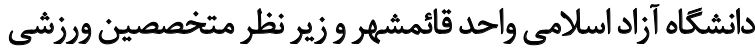
با رعايت نكات اخلاقى، حفظ ايمنى و سلامث آزمودنى هانها انجام

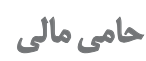

اين مقاله بركرفته از باياننامه كارشناسى ارشد نويسنده اول،

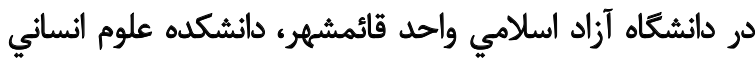
بوده است. 


\section{References}

[1] Xu HW, Yi YY, Zhang SB, Hu T, Wang SJ, Zhao WD, et al. Does vitamin $D$ status influence lumbar disc degeneration and low back pain in postmenopausal women? A retrospective singlecenter study. Menopause. 2020; 27(5):586-92. [DOI:10.1097/ GME.0000000000001499] [PMID]

[2] Lodh M, Goswami B, Mahajan RD, Sen D, Jajodia N, Roy A. Assessment of vitamin $D$ status in patients of chronic low back pain of unknown etiology. Indian J Clin Biochem. 2015; 30(2):174-9. [DOI:10.1007/s12291-014-0435-3] [PMID] [PMCID]

[3] Cai C. Treating vitamin D deficiency and insufficiency in chronic neck and back pain and muscle spasm: A case series. Perm J. 2019; 23:18-241. [DOI:10.7812/TPP/18.241] [PMID] [PMCID]

[4] Ghai B, Bansal D, Kanukula R, Gudala K, Sachdeva N, Dhatt SS, et al. Vitamin D supplementation in patients with chronic low back pain: An open label, single arm clinical trial. Pain Physician. 2017; 20(1):E99-105. [DOI:10.36076/ppj.2017.1.E99] [PMID]

[5] Wiciński M, Adamkiewicz D, Adamkiewicz M, Śniegocki $M$, Podhorecka M, Szychta P, et al. Impact of vitamin D on physical efficiency and exercise performance-a review. Nutrients. 2019; 11(11):2826. [DOI:10.3390/nu11112826] [PMID] [PMCID]

[6] Putz-Bankuti C, Pilz S, Stojakovic T, Scharnagl H, Pieber TR, Trauner $M$, et al. Association of 25-hydroxyvitamin D levels with liver dysfunction and mortality in chronic liver disease. Liver Int. 2012; 32(5):845-51. [DOI:10.1111/j.14783231.2011.02735.x] [PMID]

[7] Zúñiga S, Firrincieli D, Housset C, Chignard N. Vitamin D and the vitamin D receptor in liver pathophysiology. Clin Res Hepatol Gastroenterol. 2011; 35(4):295-302. [DOI:10.1016/j. clinre.2011.02.003] [PMID]

[8] Guo GY, Shi YQ, Wang L, Ren X, Han ZY, Guo CC, et al. Serum vitamin $D$ level is associated with disease severity and response to ursodeoxycholic acid in primary biliary cirrhosis. Aliment Pharmacol Ther. 2015; 42(2):221-30. [DOI:10.1111/apt.13244] [PMID]

[9] Potter JJ, Liu X, Koteish A, Mezey E. 1,25-dihydroxyvitamin D3 and its nuclear receptor repress human $\alpha 1(\mathrm{I})$ collagen expression and type I collagen formation. Liver Int. 2013; 33(5):67786. [DOI:10.1111/liv.12122] [PMID] [PMCID]

[10] Habibzadeh Bizhani F, Habibian M, Farzanegi P. Effect of 8 weeks aerobic exercise and vitamin $C$ on liver transaminases activities in obese 8-11 years girls. J Gorgan Univ Med Sci. 2017; 19(1):25-32. [In Persian] http://goums.ac.ir/journal/article-1-3014-en.html

[11] Targher G, Day CP, Bonora E. Risk of cardiovascular disease in patients with nonalcoholic fatty liver disease. N Engl J Med. 2010; 363(14):1341-50. [DOI:10.1056/NEJMra0912063] [PMID]

[12] Chalasani N, Younossi Z, Lavine JE, Diehl AM, Brunt EM, Cusi $\mathrm{K}$, et al. The diagnosis and management of non-alcoholic fatty liver disease: Practice guideline by the American Association for the study of liver diseases, American College of Gastroenterology, and the American Gastroenterological Association. Hepatology. 2012; 55(6):2005-23. [DOI:10.1002/hep.25762] [PMID]
[13] Skaaby T, Husemoen LLN, Borglykke A, Jørgensen T, Thuesen $\mathrm{BH}$, Pisinger $\mathrm{C}$, et al. Vitamin D status, liver enzymes, and incident liver disease and mortality: A general population study. Endocrine. 2014; 47(1):213-20. [DOI:10.1007/s12020-0130107-8] [PMID]

[14] Alie M, Matinhomaee $H$, Azarbayjani\&Irm MA, Peeri M. The effect of different resistance training intensities on liver function in obese men. J Sport Biosci. 2017; 9(1):75-92. [In Persian] [DOI:10.22059/JSB.2017.61910]

[15] Abd El-Kader SM, Al-Jiffri OH, Al-Shreef FM. Liver enzymes and psychological well-being response to aerobic exercise training in patients with chronic hepatitis C. Afr Health Sci. 2014; 14(2):414-9. [DOI:10.4314/ahs.v14i2.18] [PMID] [PMCID]

[16] Keating SE, Machan EA, O'Connor HT, Gerofi JA, Sainsbury A, Caterson ID, et al. Continuous exercise but not high intensity interval training improves fat distribution in overweight adults J Obes. 2014; 2014:834865. [DOI:10.1155/2014/834865] [PMID] [PMCID]

[17] Sadeghi S, Asad MR, Ferdosi MH. The effect of twelve weeks endurance training on liver enzymes levels in Iranian obese women. J Res Sport Med Technol. 2017; 15(13):49-60. [In Persian] http:// jsmt.khu.ac.ir/article-1-213-en.htm

[18] Naderi E. Does obesity affect the efficacy of therapeutic exercise on pain intensity and disability in patients with chronic non-specific low back pain? J Anesthesiol Pain. 2017; 8(2):71 83. [In Persian] http://jap.iums.ac.ir/article-1-5317-en.htm

[19] Alper BS, Shah A, Malone-Moses M, Manheimer EW, Ehrlich A. Point-of-care application of: Guidelines and evidence on acupuncture for chronic low back pain. Eur J Integr Med. 2016; 8(4):326-8. [DOI:10.1016/j.eujim.2016.07.029]

[20] Hjinajaf S, Mohammadi F, Azizi M. Effect of aerobic interval exercise training on serum levels of 25-hydroxyvitamin D and indices anthropometry in overweight and obesity patients. Jundishapur Sci Med J. 2018; 17(1):37-48. [In Persian] http:// jsmj.ajums.ac.ir/article_59633.html?lang=en

[21] Al Faraj S, Al Mutairi Kh. Vitamin D deficiency and chronic low back pain in Saudi Arabia. Spine (Phila Pa 1976). 2003; 28(2):177-9. [DOI:10.1097/00007632-200301150-00015] [PMID]

[22] Izadi A, Aliasghari F, Pourghassem Gargari B, Ebrahimi S. Strong association between serum vitamin $D$ and vaspin levels, AIP, VAl and liver enzymes in NAFLD patients. Int J Vitam Nutr Res. 2020; 90(1-2):59-66. [DOI:10.1024/0300-9831/ a000443] [PMID]

[23] Komolmit P, Kimtrakool S, Suksawatamnuay S, Thanapirom K Chattrasophon $\mathrm{K}$, Thaimai $\mathrm{P}$, et al. Vitamin $\mathrm{D}$ supplementation improves serum markers associated with hepatic fibrogenesis in chronic hepatitis $C$ patients: A randomized, doubleblind, placebo-controlled study. Sci Rep. 2017; 7(1):8905 [DOI:10.1038/s41598-017-09512-7] [PMID] [PMCID]

[24] Nadjarzadeh A, Jani N, Khoshnevisan M, Molajaafari A, Fallahzadeh $\mathrm{H}$, Khabiri $\mathrm{F}$, et al. Effects of low caloric diet with and without vitamin $D$ supplementation on anthropometric parameters in patients with non-alcoholic fatty liver. Toloo-e Behdasht. 2016; 14(6):410-22. [In Persian] http://tbj.ssu.ac.ir/ article-1-2031-en.html 
[25] Papapostoli I, Lammert F, Stokes CS. Effect of short-term Vitamin D correction on hepatic steatosis as quantified by Controlled Attenuation Parameter (CAP). J Gastrointestin Liver Dis. 2016; 25(2):175-81. [DOl:10.15403/jgld.2014.1121.252.cap] [PMID]

[26] Pilz S, Putz-Bankuti C, Gaksch M, Spindelboeck W, Haselberger $M$, Rainer $F$, et al. Effects of vitamin $D$ supplementation on serum 25-hydroxyvitamin $D$ concentrations in cirrhotic patients: A randomized controlled trial. Nutrients. 2016; 8(5):278. [DOI:10.3390/nu8050278] [PMID] [PMCID]

[27] Tabrizi R, Moosazadeh M, Lankarani KB, Akbari M, Heydari ST, Kolahdooz $F$, et al. The effects of vitamin $D$ supplementation on metabolic profiles and liver function in patients with non-alcoholic fatty liver disease: A systematic review and meta-analysis of randomized controlled trials. Diabetes Metab Syndr. 2017; 11 Suppl 2:S975-82. [DOI:10.1016/j.dsx.2017.07.025] [PMID]

[28] Zhuang P, Sun S, Dong R, Chen G, Huang Y, Zheng S. Associations between vitamin $D$ and liver function and liver fibrosis in patients with biliary Atresia. Gastroenterol Res Pract. 2019; 2019:4621372. [DOI:10.1155/2019/4621372] [PMID] [PMCID]

[29] Finkelmeier F, Kronenberger B, Zeuzem S, Piiper A, Waidmann $\mathrm{O}$. Low 25 -hydroxyvitamin $D$ levels are associated with infections and mortality in patients with cirrhosis. PLoS One. 2015; 10(6):e0132119. [DOI:10.1371/journal.pone.0132119] [PMID] [PMCID]

[30] Aghah M, Daryanoosh F, Moeini M, Mohamadi M, Fatahi MR. The effect of 12 weeks vitamin $E$ supplemention and aerobic training on liver enzymes of non-alcoholic steatohepatitis patients. Armaghane Danesh. 2017; 21(10):964-75. [In Persian] http://armaghanj.yums.ac.ir/article-1-1481-en.html

[31] Kaki A, Galedari M. The effect of 12 weeks high intensity interval training and resistance training on liver fat, liver enzymes and insulin resistance in men with nonalcoholic fatty liver. Jundishapur Sci Med J. 2017; 16(5):493-503. [In Persian] [DOI:10.22118/JSMJ.2017.53990]

[32] Kistler KD, Brunt EM, Clark JM, Diehl AM, Sallis JF, Schwimmer JB, et al. Physical activity recommendations, exercise intensity, and histological severity of nonalcoholic fatty liver disease. Am J Gastroenterol. 2011; 106(3):460-8. [DOI:10.1038/ ajg.2010.488] [PMID] [PMCID]

[33] Nabizadeh Haghighi A, Shabani R. Comparing effects of medication therapy and exercise training with diet on liver enzymes levels and liver sonography in patients with Non-Alcoholic Fatty Liver Disease (NAFLD). J Fasa Univ Med Sci. 2016; 5(4):488500. [In Persian] http://journal.fums.ac.ir/article-1-774-en.html

[34] Moosavi SJ, Habibian M, Farzanegi P. The effect of regular aerobic exercise on plasma levels of 25 - hydroxy vitamin $D$ and insulin resistance in hypertensive postmenopausal women with type 2 diabetes. Razi J Med Sci. 2016; 22(141):80-90. [In Persian] http://rjms.iums.ac.ir/article-1-3402-en.html 
This Page Intentionally Left Blank 